\title{
Ovarian Hilus
}

National Cancer Institute

\section{Source}

National Cancer Institute. Ovarian Hilus. NCI Thesaurus. Code C61449.

A depression in the ovary where the ovarian ligament attaches and blood vessels and nerves enter or leave the ovary. 